\title{
Histomorphometric features of ventral prostate in different aged rats after central ghrelin treatment
}

\author{
Bosiljka A. Plecas-Solarovic ${ }^{1}$, Dejan M. Nesic ${ }^{2}$, Darko M. Stevanovic ${ }^{2}$, Aleksandar Lj. \\ Obradovic $^{1}$, Marina N. Djelic ${ }^{2}$, Verica Lj. Milosevic ${ }^{3}$ and Vesna P. Starcevic ${ }^{2}$ \\ ${ }^{1}$ Institute of Physiology, Faculty of Pharmacy, University of Belgrade, 11000 Belgrade, Serbia \\ ${ }^{2}$ Institute of Medical Physiology, School of Medicine, University of Belgrade, 11000 Belgrade, Serbia \\ ${ }^{3}$ Institute for Biological Research "Sinisa Stankovic", University of Belgrade, 11060 Belgrade, Serbia
}

\begin{abstract}
Ghrelin, the endogenous ligand of growth hormone secretagogue receptor type 1a (GHS-R1a), has emerged as pleiotropic modulator of diverse biological functions, including energy homeostasis and recently, reproduction. The influence of intracerebroventricularly (ICV) administered ghrelin $(1 \mu \mathrm{g} / \mathrm{day} / \mathrm{rat}$ for 5 days) to rats of different ages, i.e., peripubertal (38 days), adult (60 days) and middle-aged (180 days) on the ventral prostate size and morphology, serum testosterone levels and testis weight was examined. Ghrelin treatment significantly increased $(p<0.05)$ absolute ventral prostate weight in peripubertal and middle-aged rats, by $27 \%$ and $37 \%$ respectively, due to enhancement of epithelial and/or luminal compartment of the gland. In adult rats, both absolute and relative volumes of the acinar lumen were significantly decreased $(p<0.05)$, by $38 \%$ and $44 \%$ respectively, which was associated with significant increases $(p<0.05)$ in relative and absolute volumes of interacinar stroma, whereas ventral prostate weigh was unchanged. Irrespective of animal age, ghrelin did not affect serum testosterone levels. These are the first results of ghrelin treatment effects on healthy prostate appearance, which allow us to conclude that the rat ventral prostate response to ghrelin depends on the developmental stage of animals. Our results merit further investigations and may have clinical implications, especially in the light of data on possible role of ghrelin in prostate hypertrophy and adenomas.
\end{abstract}

Key words: Ghrelin - Ventral prostate - Rats

\section{Introduction}

Ghrelin was identified as a novel neuroendocrine signal involved in the physiological control of growth hormone (GH) secretion and energy homeostasis (Kojima et al. 1999; Takaya et al. 2000; Tschop et al. 2000; Wren et al. 2000). In the last years an "unexpected" reproductive facet of ghrelin emerged and indicated that circulating ghrelin might contribute to the functional control of the reproductive axis and its integration with energy balance (Barreiro and Tena-Sempere 2004; Lorenzi et al. 2009). Significant amount of data gathered so far indicate that ghrelin par-

Correspondence to: Bosiljka Plecas-Solarovic, Institute of Physiology, Faculty of Pharmacy, University of Belgrade, Vojvode Stepe 450, 11221 Belgrade, Serbia

E-mail: bosilika.plecas@pharmacy.bg.ac.rs ticipates in the regulation of reproductive physiology by two distinct, probably overlapping pathways: (i) through systemic release of the stomach-derived peptide, which acts at all levels of hypothalamic-pituitary-gonadal (HPG) axis, and (ii) through biological actions of locally expressed ghrelin on reproductive organs (Tanaka et al. 2001; Lorenzi et al. 2009).

Data available in literature strongly suggest that ghrelin predominantly acts as an inhibitory signal for the pituitary-gonadal axis in different mammalian species including rodents, sheep, non-human primates and humans; a phenomenon that might contribute to the well known suppression of gonadotropin levels in conditions of persistent negative energy balance, in which ghrelin levels are commonly elevated (Tena-Sempere 2008; Roa et al. 2010). Thus, it have been reported that systemic administration of ghrelin to pubertal male rats significantly increased gonadotropin 
releasing hormone $(\mathrm{GnRH})$ interpulse interval, whereas in vitro, when the peptide was incubated with hypothalamic explants, a reduction of interpulse interval was observed (Lebrethon et al. 2007). The effects of ghrelin on the pituitary function are dependent upon the nature of experimental model used (Lim et al. 2011). Chronic administration of ghrelin consistently decreased luteinizing hormone (LH) secretion in pubertal and adult male rats (Martini et al. 2006). Similarly, a 20-day ghrelin treatment of young adult male rats reduced plasma LH and testosterone, but only in animals exposed to food restriction (Sirotkin et al. 2008). Central application of ghrelin significantly decreased serum levels of LH in intact and orchidectomized peripubertal rats, while in vitro ghrelin stimulated the secretion of both gonadotropins (Fernandez-Fernandez et al. 2004). Studies on the influence of ghrelin on puberty onset in rats suggest that elevated ghrelin levels exert inhibitory actions in both males and females, primary via reduced gonadotropin level, and that males appear to be more sensitive (Martini et al. 2006). Ghrelin and its receptor GHS Rla are expressed in rat and human gonads (Tena-Sempere et al. 2002; Gaytan et al. 2004). Finally, ghrelin is shown to affect testis size and structure (Sirotkin et al. 2008; Kheradmand et al. 2009) and to modulate testosterone secretion, androgen receptor expression, Leydig cell proliferation and seminiferous tubule gene expression (Barreiro et al. 2004; Kheradmand et al. 2009; Wang et al. 2011).

In normal human prostate, both ghrelin and GHS-R1a are present at the level of mRNA expression (Gnanapavan et al. 2002), but any cellular confirmatory assessment is still lacking, probably due to a very low intracellular concentrations. In addition, a low activity of the newly identified ghrelin acylation enzyme, ghrelin $o$-acyltransferase was detected in human prostate (Lim et al. 2011). In clear contrast to healthy prostate tissue, ghrelin and its receptor are highly expressed in prostate carcinomas (Jeffery et al. 2002, 2003) and the peptide has been shown to increase the proliferation of prostate cancer cell line in vitro by $33 \%$ (Jeffery et al. 2002). In light of these data and the lack of results concerning the response of healthy prostate tissue to ghrelin treatment, the aim of our work was to examine whether the repetitive ICV administration of ghrelin to male rats of different ages affects the ventral prostate size and structure.

\section{Material and Methods}

\section{Experimental animals}

Wistar male rats of different age, i.e. peripubertal, adult and middle-aged, bred at the Institute of Biomedical Research "Galenika" (Belgrade, Serbia) were used in the study. They were kept individually in metabolic cages under constant laboratory conditions of room temperature $\left(22 \pm 2^{\circ} \mathrm{C}\right)$ and lighting (12 h light : $12 \mathrm{~h}$ dark), and were fed with standard pelleted rat food ("D.D. Veterinarski zavod Subotica", Subotica, Serbia). Food and water were available ad libitum and the animals were accustomed to daily handling.

\section{Surgical procedure}

The surgical procedure was performed under deep anesthesia (Thiopental-Sodium, $45 \mathrm{mg} / \mathrm{kg}$, i.p., Rotexmedica, Trittau, Germany) and equipped with headset for ICV injection, consisting of a silastic-sealed 20-gauge cannula positioned in the right lateral cerebral ventricle $(1 \mathrm{~mm}$ posterior and $1.5 \mathrm{~mm}$ lateral to the bregma, and $3 \mathrm{~mm}$ below the cortical surface) (Starcevic et al. 1988). A small stainless steel anchor screw was placed at a remote site on the skull. The cannula and screw were cemented to the skull with standard dental acrylic (Sigma; ICN Galenika, Belgrade, Serbia). Following surgery, the animals received a single dose of s.c. $0.28 \mathrm{mg} / \mathrm{kg}$ buprenorphin (Buprenex; Reckitt Benckiser Healthcare) and 5 days of recovery was allowed before experiments.

\section{Treatment}

The animals of the same age were randomly divided in 2 groups $(n=5)$ : experimental and control. Body weights were obtained daily, just before the intracerebroventricularly (ICV) injections. The mean \pm SEM pre-treatment body weight of peripubertal (38-day old), adult (60-day old) and middle-aged (180-day old) rats, were $123.0 \pm 2.0 \mathrm{~g} ; 202.0 \pm$ $7.0 \mathrm{~g}$ and $420.0 \pm 11.0 \mathrm{~g}$. Experimental group was treated ICV with $1 \mu \mathrm{g}$ of ghrelin (Global Peptide Services, Fort Collins, CO, USA) dissolved in $5 \mu$ l phosphate-buffered saline (PBS)/day over 5 consecutive days. The dose of ghrelin used in this experiment was based on our previous studies related to ICV ghrelin actions on the anterior pituitary secretion (Stevanovic et al. 2006; Milosevic et al. 2010). The control group received $5 \mu \mathrm{l}$ of PBS according to the same schedule. The ICV injections were made at 10:00 h. The rats were decapitated under deep i.p. thiopental sodium anesthesia $1 \mathrm{~h}$ after the last ICV injection. The blood was collected for testosterone concentration analysis and the rat tissues (ventral prostate, the left testis and pituitary) were dissected out and weighed. Experimental protocol was approved by the Local Animal Care Committee, School of Medicine, University of Belgrade and the animals received human care during experimental period.

\section{Testosterone assay}

The sera were separated after centrifugation of trunk blood at $3000 \mathrm{rpm}$ for $20 \mathrm{~min}$ and stored at $-20^{\circ} \mathrm{C}$ until assayed. 
Testosterone levels were measured using a commercial EIAgen Testosterone Kit (Adaltis, Italia). The sensitivity of this method, calculated as two times the standard deviation from standard value (Bo), is $0.01 \mathrm{ng} / \mathrm{ml}$ when the value of measured value (B)/Bo (\%) is approx $90 \%$. The inter- and intra-run precision had a coefficient of variation of $3.9 \%$ and $6.2 \%$, respectively.

\section{Morphometric analysis}

The ventral prostates were carefully removed, weighed and immediately fixed in Bouin's solution for $48 \mathrm{~h}$. The tissue specimens were then dehydrated through a graded series of ethyl alcohol, cleared in xylene, and embedded in paraplast. They were serially cut into 5 - $\mu \mathrm{m}$-thick sections and the intermediate and distal sections of the gland, identified according to Banerjee et al. (1998), were stained with hematoxylin and eosin.

Morphometric analysis was performed by a simple point counting method (Weibel and Gomez 1962; Plecas et al. 1992, 1997) using Olympus BX 50 microscope (Olympus Optical Co., GmbH, Hamburg, Germany) and image analysis software (Micro Image Version 4.0, Olympus). For each of 5 sections per animal images of 15 to 20 non-overlapping fields, depending on the size of specimen, were captured separately at total magnification of $100 \times$ and each digitalized image was saved. The prostate tissue was divided into stromal and glandular compartment and the latter was subdivided into epithelium and lumen. Each captured image was overlaid with $A_{100}$ test grid (the test frame containing 100 intersection points) and the test points hitting the particular tissue component was scored. The area percentage, which is equivalent to volume percentage (density) of each component, was calculated. The volume (absolute volume) of each compartment was determined by multiplying the volume density by the prostate weight based on determination that $1 \mathrm{mg}$ of fresh rat ventral prostate tissue had a volume of approximately $1 \mathrm{~mm}^{3}$ (DeKlerk and Coffey 1978).

\section{Statistical analysis}

The data are presented as group means \pm SEM for 5 animals in each group. Two-group (ghrelin-treated and age-matched control) comparisons were analyzed by the nonparametric Mann-Whitney test; serum testosterone concentrations in control groups of different ages were compared with the Kruskal-Wallis ANOVA followed by the Dunn's multiple comparison test. The statistical package GraphPad Prism 5.0 was used. Probability value of $5 \%$ or less was considered statistically significant.

\section{Results}

\section{Body weight gain and organ weights}

The influence of 5 consecutive days ICV ghrelin injections on body weight gain, ventral prostate, testis and pituitary weights in rats of different ages (38-, 60- and 180-day old) at the end of the treatment are summarized in Table 1.

Ghrelin treatment significantly increased body weight gain in rats of all ages. Compared with age-matched control groups, the increases were $37 \%$ in peripubertal, $67 \%$ in adult and $41 \%$ in middle-aged rats $(p<0.05)$. The treatment significantly $(p<0.05)$ augmented ventral prostate absolute weight in peripubertal and middle-aged rats $(28 \%$ and $37 \%$, respectively), whereas testis absolute weight was only increased in peripubertal animals (17\%). However, relative weights of these organs were unaffected by ghrelin treatment. In addition, ghrelin administration significantly $(p<0.05)$ increased both the absolute and relative pituitary weights in peripubertal $(35 \%$ and $18 \%$, respectively) and middle-aged (43\% and $32 \%$, respectively) rats when compared to corresponding controls.

\section{Histomorphometry of ventral prostate}

Ghrelin administration resulted in marked changes of the ventral prostate morphometrical parameters at all three

Table 1. The effects of ICV-administered ghrelin on body weight gain, ventral prostate, testis, and pituitary relative and absolute weights in rats of different ages: peripubertal (38-day old), adult (60-day old) and middle-aged (180-day old)

\begin{tabular}{|c|c|c|c|c|c|c|c|c|}
\hline \multirow{2}{*}{ Group } & & \multirow{2}{*}{$\begin{array}{l}\text { BW gain } \\
(\mathrm{g})\end{array}$} & \multicolumn{3}{|c|}{ Absolute weight (mg) } & \multicolumn{3}{|c|}{ Relative weight (mg/100 g BW) } \\
\hline & & & Ventral prostate & Testis & Pituitary & Ventral prostate & Testis & Pituitary \\
\hline \multirow{2}{*}{ Peripubertal } & Control & $33.2 \pm 0.2$ & $36.0 \pm 2.0$ & $645.0 \pm 9.0$ & $3.50 \pm 0.1$ & $23.7 \pm 0.9$ & $424.0 \pm 3.0$ & $2.3 \pm 0.1$ \\
\hline & Ghrelin & $45.6 \pm 1.3^{*}$ & $46.0 \pm 2.0^{*}$ & $755.0 \pm 21.0^{* *}$ & $4.7 \pm 0.2^{\star}$ & $26.6 \pm 0.7$ & $436.0 \pm 7.0$ & $2.7 \pm 0.1^{* *}$ \\
\hline \multirow{2}{*}{ Adult } & Control & $19.8 \pm 1.4$ & $165.0 \pm 7.0$ & $1261.0 \pm 39.0$ & $8.0 \pm 0.4$ & $70.2 \pm 2.4$ & $535.0 \pm 11.0$ & $3.4 \pm 0.1$ \\
\hline & Ghrelin & $33.0 \pm 1.5^{\star *}$ & $154.0 \pm 4.0$ & $1199.0 \pm 41.0$ & $7.1 \pm 0.5$ & $70.4 \pm 4.3$ & $544.0 \pm 13.0$ & $3.2 \pm 0.1$ \\
\hline \multirow{2}{*}{ Middle-aged } & Control & $35.2 \pm 1.0$ & $552.0 \pm 36.0$ & $1349.0 \pm 49.0$ & $8.9 \pm 0.2$ & $125.0 \pm 10.0$ & $304.0 \pm 13.0$ & $2.0 \pm 0.1$ \\
\hline & Ghrelin & $49.6 \pm 3.0^{*}$ & $754.0 \pm 48.0^{\star *}$ & $1611.0 \pm 66.0$ & $12.7 \pm 0.3^{*}$ & $157.0 \pm 11.0$ & $336.0 \pm 18.0$ & $2.6 \pm 0.1^{\star *}$ \\
\hline
\end{tabular}

The values are expressed as means \pm SEM for 5 animals; ${ }^{\star} p<0.05$; ${ }^{\star *} p<0.01$ vs. corresponding controls. BW, body weight. 


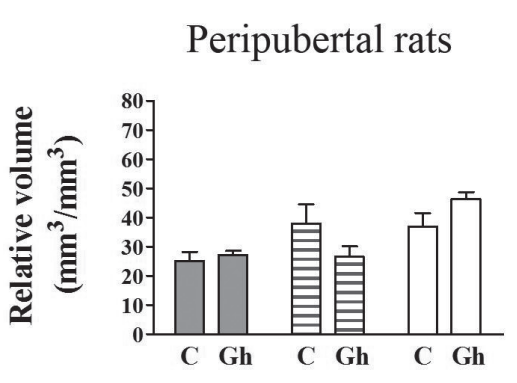

Young adult rats
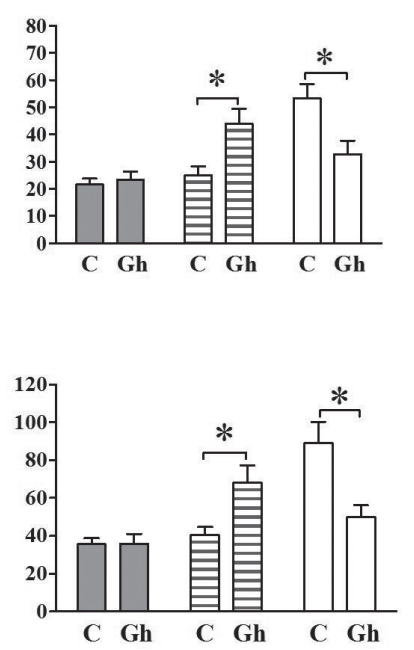

Middle-aged rats
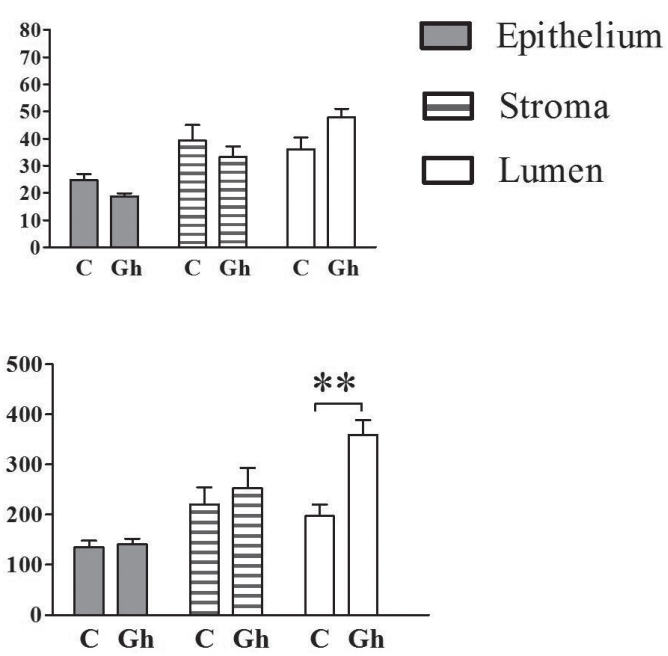

Figure 1. Morphometric parameters of the ventral prostate of rats ICV-injected with ghrelin (Gh; $1 \mu \mathrm{g} /$ day) or vehicle (C) for 5 days in relation to age. All data are expressed as mean \pm SEM; $n=5$ animals per group; ${ }^{\star} p<0.05 ;{ }^{* *} p<0.01 v s$. age-matched control rats.

postnatal periods examined, but not in the same manner (Fig. 1). No signs of cytologic atypia or abnormal proliferation were observed in ghrelin-treated groups.

In the ventral prostate of ghrelin-treated peripubertal rats absolute volumes of glandular epithelium and lumen were significantly $(p<0.05)$ increased $(41 \%$ and $64 \%$, respectively), although there were no significant $(p>0.05)$ alterations in the relative volumes of the ventral prostate compartments (Fig. 1). No appreciable qualitative histological alterations were noted in the ventral prostate of ghrelintreated peripubertal rats comparing to controls of the same age (Fig. 2A and B).

Ventral prostates of ghrelin-treated adult rats responded to treatment by significant changes in both relative and absolute volumes of luminal and stromal compartments comparing to age-matched controls (Fig. 1), although the glandular weight was not altered (Tab. 1). Thus, both relative and absolute volumes of the luminal compartment were significantly $(p<0.05)$ reduced $(38 \%$ and $44 \%$, respectively) whereas these parameters of the interacinar stroma were significantly $(p<0.05)$ increased $(76 \%$ and $67 \%$, respectively). A histological examination of the ghrelin-treated ventral prostates revealed that atrophic acini of irregular shape were accompanied by a stromal hypertrophy (Fig. $2 \mathrm{D}$ vs. C).

In middle-age rats, administration of ghrelin did not affect $(p>0.05)$ relative volumes of the ventral prostate compartments, but it significantly $(p<0.05)$ increased (81\%) the absolute volume of glandular lumen (Fig. 1). A cospicuous engorgement of the acini, as evidenced by an accumulation in eosinophylic staining in the lumen, with corresponding distension of the epithelium, which became cuboidal, was observed in the gland from ghrelin-treated rats (Fig. 2F) comparing to corresponding control tissue (Fig. 2E).

\section{Serum testosterone levels}

No change $(p>0.05)$ in serum testosterone concentration was evidence in ghrelin-treated rats of any age examined when compared to values found in age-matched controls (Fig. 3). Of note, as expected, among control groups of different ages the highest testosterone concentration was determined in adult rats; its value was significantly (2-fold) higher than in peripubertal as well as in middle-age group, although the latter difference did not reach statistical significance due to a well-known high individual variations in serum testosterone levels (Benerjee et al. 1998).

\section{Discussion}

In the present study, the possible influence of repeated ICV ghrelin administration on the ventral prostate size and morphology of rats of different ages was investigated. The obtained results showed for the first time that ghrelin treatment affected the rat prostate gland and that the effect was not mediated by testosterone, but depended on developmental stage of the animals, and hence of their androgen status. In peripubertal (38 days) and middle-aged (180 days) rats, in which initial serum testosterone levels 

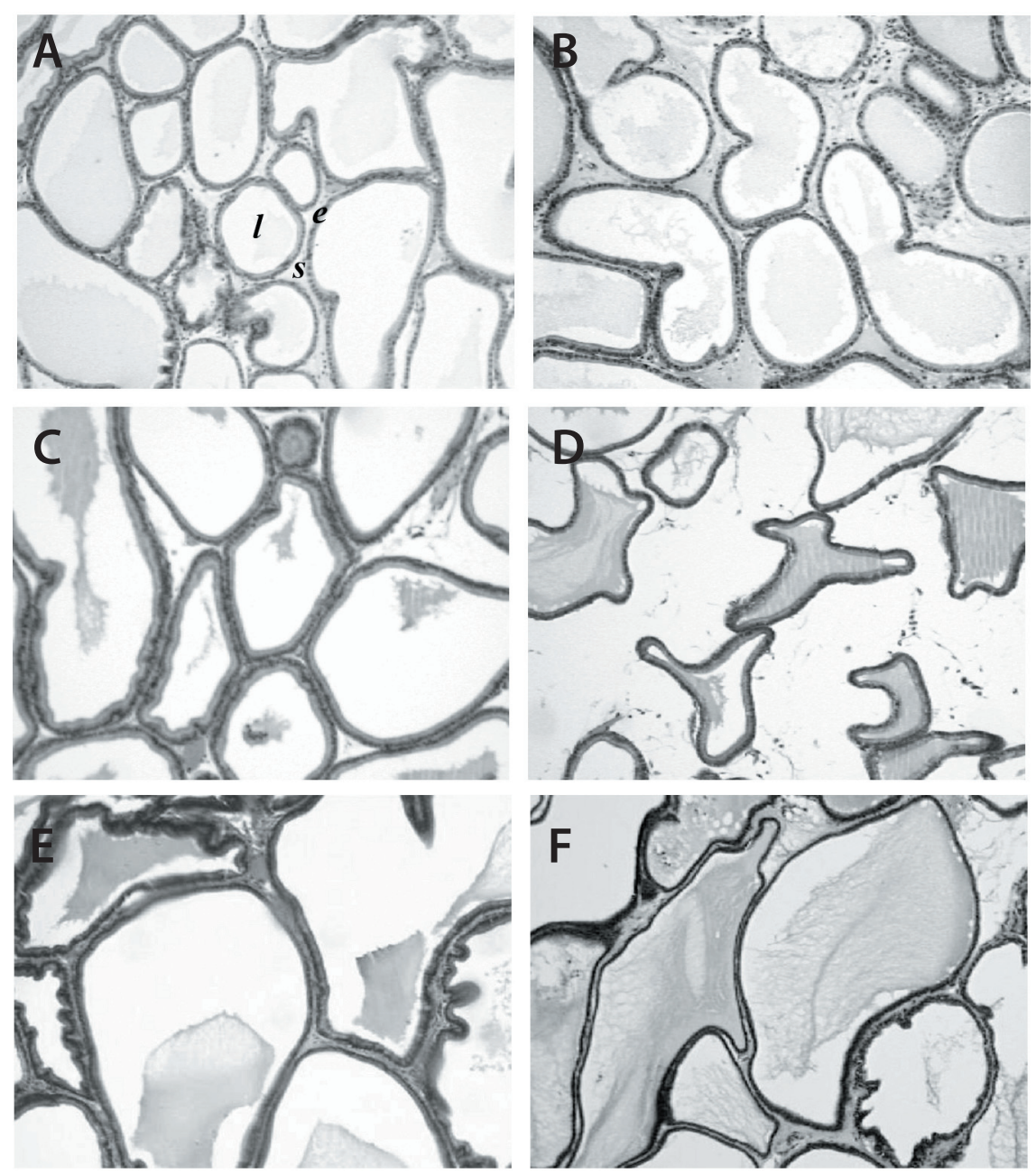

Figure 2. Effect of ICV ghrelin treatment ( $1 \mu \mathrm{g} /$ day for 5 days) on the ventral prostate in relation to age. Representative photomicrographs stained with hematoxylin and eosin, at original magnification 100x: controls of different age (A, 38 days; C, 60 days; E, 180 days) and ghrelin-treated rats of corresponding age (B, 38 days; $\mathbf{D}, 60$ days, $\mathbf{F}, 180$ days). e, epithelium; s, interacinar stroma; l, lumen.

were markedly lower than in adult ones, ghrelin treatment resulted in significant increase in ventral prostate weight as a consequence of significant enlargements of epithelial and/or luminal compartments. In adult rats (60 days), with high initial serum testosterone levels, ghrelin application did not affect glandular weight, but evoked a reduction in the volume of luminal compartment with corresponding increase in the volume of fibromuscular stroma. Such agerelated differences in the effect of ghrelin treatment were probably due to different physiological levels of ghrelin actions.

Ghrelin treatment did not change serum testosterone levels at the end of the treatment at any age. This finding is in contradiction with a number of data showing mainly inhibitory influence of the peptide on LH and/or testosterone secretion in different experimental conditions (Tena-Sem-

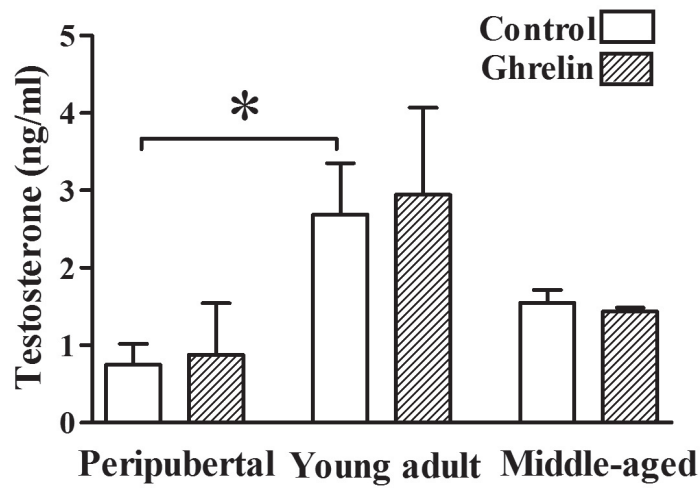

Figure 3. Serum testosterone concentrations in ICV ghrelin-treated rats $(1 \mu \mathrm{g} /$ day for 5 days) and vehicle-injected control animals in relation to age. All data are expressed as mean \pm SEM; $n=5$ animals per group; ${ }^{*} p<0.05$. 
pere et al. 2002; Barreiro and Tena-Sempere 2004; Fernandez-Fernandez et al. 2004; Martini et al. 2006; Sirotkin et al. 2008; Wang et al. 2011). However, no effect or stimulatory effect of ghrelin on LH or testosterone secretion were observed as well (Fernandez-Fernandez et al. 2004; Martini et al. 2006; Sirotkin et al. 2008; Wang et al. 2011), depending on the different experimental designs. The lack of ghrelin influence on serum testosterone levels in our experiments could be explained, most likely, by the fact that pituitary-gonadal axis response to this peptide depended on different factors such as developmental stage, strain, doses, and patterns of ghrelin administration (Martini et al. 2006). Importantly, the dose of ghrelin used in our study $(1 \mu \mathrm{g} / \mathrm{rat} /$ day $)$ was several (approx. 3 to 10) times lower than those that influenced LH or testosterone secretion in vivo in other studies (FernandezFernandez et al. 2004; Wang et al. 2011).

Obviously, the changes in the ventral prostate size and structure observed in this study cannot be ascribed to alterations in serum testosterone, the hormone which plays major role in the regulation of prostate growth and function. However, other hormones, including $\mathrm{GH}$, are involved in prostate physiology and pathology (Ruan et al. 1999; Un-no et al. 2007; Simanainen et al. 2011). Since ghrelin is a potent physiological stimulator of $\mathrm{GH}$ secretion both in vivo and in vitro (Kojima et al. 1999; Seoane et al. 2000; Stevanovic et al. 2006), there is strong evidence that $\mathrm{GH}$ and its peripheral mediator of action, insulin-like growth factor I (IGF I) are implicated in the prostate growth and function. In prostate, GH has been shown to stimulate expression of several mRNAs: for androgen receptor, GH receptor, IGF I, IGF I receptor and 5- $\alpha$ reductases (Reiter et al. 1992, 1995). In addition, elevated plasma concentrations of IGF I is linked to a higher risk for prostate cancer (Ryan and Goss 2008).

Previously, we demonstrated that ghrelin, given according to the same dosing protocol as in this study, stimulated rat somatotrope proliferation and significantly increased serum GH (Stevanovic et al. 2006). Therefore, we consider that, in peripubertal and middle-aged rats used in this study, GH secretion was also stimulated by ghrelin. Significantly increased body weight gain and the weights of all organs measured are in a good agreement with this finding.

As for the ventral prostate, the absolute weights were significantly increased in both peripubertal and middle-aged ghrelin-treated rats. Since there were no significant changes in the relative weights of the gland, we concluded that ventral prostate size increased proportionally to overall body weight increase, which indicated a somatotropic regulation. Such regulation was manifested as a proliferative-secretory response in the ventral prostates of peripubertal group in which the volumes of epithelial and luminal compartments were significantly enhanced. These findings are in accordance with the data showing that, like testosterone, GH/IGF $\mathrm{I}$ is essential for normal development of prostate epithelial and luminal compartments (Ruan et al. 1999). In middleaged rats, only the luminal absolute volume was significantly increased. An engorgement of the lumen with corresponding distension of epithelium resulted in a predominant contribution of this compartment to the ventral prostate weight. Besides, a negative effect of accumulated secretion on the epithelium is proposed (Vilamaior et al. 2006), which is in agreement with a flattened epithelium observed in the middle-age rat ventral prostates. Similar responses of peripubertal and middle-aged rat ventral prostates to $\mathrm{GH}$, elicited by ghrelin treatment, is possible since the sensitivity of the rat pituitary gland to exogenous ghrelin, in terms of GH secretion, appeared to be unaffected by aging (Sun et al. 2007).

Adult rats responded to ghrelin treatment quite differently; their body weight gain was significantly increased, but no changes in the ventral prostate, testis and pituitary weights were found. Accordingly, there are no compelling confirmations in favor of stimulated GH secretion in these animals. In addition, morphological changes in the ventral prostates are not compatible with the well-known GH/IFG I action on the gland. In spite of unchanged weight, an atrophy of acini was observed and both relative and absolute volumes of luminal compartment were reduced. At the same, increased relative and absolute volumes of the fibromuscular stroma indicated a hypertrophy of this compartment. Such histological manifestations are indicative of an inhibitory influence on the ventral prostate. The mechanism of this action remains unclear. We can assume that ghrelin treatment in adult rats affected the secretion of some other one or more hormones that act on the prostate. It is even possible that ghrelin by itself influence at prostate level, since the $B$ peptide crosses the mouse blood-brain barrier predominantly in the brainto-blood direction (Banks et al. 2002) and ICV ghrelin administration to rats elicits multiple increase in peripheral plasma ghrelin levels (Theander-Carillo et al. 2006; SangiaoAlvarellos et al. 2009).

In conclusion, these results report the influence of ghrelin treatment on the prostate size and structure, and show that the effect of ICV ghrelin application on the rat ventral prostate is developmental stage dependent. In animals with low initial levels of testosterone, i.e., peripubertal and middle aged, stimulation of the ventral prostate growth was found, most likely due to ghrelin-stimulated GH secretion. In adult rats, with high serum testosterone levels, an inhibitory effect of ghrelin treatment on the ventral prostate was expressed, but the mechanism of this action remains unknown. However, the results merit further investigations and may have clinical implications, especially in the light of data on possible role of ghrelin in prostate hypertrophy and adenomas.

Aknowledgements. This work was supported by the Ministry of Education and Science of Republic of Serbia, grants No. III 41025 
and ON 173009. We thank Katarini Lungulovic and Marini Dikovic for skillful technical assistance and conscientious care of the course and outcome of experiment.

\section{References}

Banerjee P. P., Banerjee S., Lai J. M., Strandberg J. D., Zirkin B. R., Brown T. R. (1998): Age-dependent and lobe-specific spontaneous hyperplasia in the brown Norway rat prostate. Biol. Reprod. 59, 1163-1170 http://dx.doi.org/10.1095/biolreprod59.5.1163

Banks W. A., Tschop M., Robinson S. M., Heiman M. L. (2002): Extent and direction of ghrelin transport across the bloodbrain barrier is determined by its unique primary structure. J. Pharmacol. Exp. Ther. 302, 822-827 http://dx.doi.org/10.1124/jpet.102.034827

Barreiro M. L., Gaytan F., Castellano J. M., Suominen J. S., Roa J., Gaytan M., Aguilar E., Dieguez C., Toppari, J., Tena-Sempere M. (2004): Ghrelin inhibits the proliferative activity of immature Leydig cells in vivo and regulates stem cell factor messenger ribonucleic acid expression in rat testis. Endocrinology 145, 4825-4834 http://dx.doi.org/10.1210/en.2004-0732

Barreiro M. L., Tena-Sempere M. (2004): Ghrelin and reproduction: a novel signal linking energy status and fertility? Mol. Cell Endocrinol. 226, 1-9 http://dx.doi.org/10.1016/j.mce.2004.07.015

DeKlerk D. P., Coffey D. S. (1978): Quantitative determination of prostatic epithelial and stromal hyperplasia by a new technique. Biomorphometrics. Invest. Urol. 16, 240-245

Fernandez-Fernandez R., Tena-Sempere M., Aguilar E., Pinilla L. (2004): Ghrelin effects on gonadotropin secretion in male and female rats. Neurosci. Lett. 362, 103-107 http://dx.doi.org/10.1016/j.neulet.2004.03.003

Gaytan F., Barreiro M. L., Caminos J. E., Chopin L. K., Herington A. C., Morales C., Pinilla L., Paniagua R., Nistal M., Casanueva F. F., Aguilar E., Dieguez C., Tena-Sempere M. (2004): Expression of ghrelin and its functional receptor, the type la growth hormone secretagogue receptor, in normal human testis and testicular tumors. J. Clin. Endocrinol. Metab. 89, 400-409 http://dx.doi.org/10.1210/jc.2003-031375

Gnanapavan S., Kola B., Bustin S. A., Morris D. G., McGee P., Fairclough P., Bhattacharya S., Carpenter R., Grossman A. B., Korbonits, M. (2002): The tissue distribution of the mRNA of ghrelin and subtypes of its receptor, GHS-R, in humans. J. Clin. Endocrinol. Metab. 87, 2988 http://dx.doi.org/10.1210/jc.87.6.2988

Jeffery P. L., Herington A. C., Chopin L. K. (2002): Expression and action of the growth hormone releasing peptide ghrelin and its receptor in prostate cancer cell lines. J. Endocrinol. 172, R7-11 http://dx.doi.org/10.1677/joe.0.172R007

Jeffery P. L., Herington A. C., Chopin L. K. (2003): The potential autocrine/paracrine roles of ghrelin and its receptor in hormone-dependent cancer. Cytokine Growth Factor Rev. 14, $113-122$ http://dx.doi.org/10.1016/S1359-6101(02)00089-8
Kheradmand A., Roshangar L., Taati M. (2009): The role of ghrelin on the morphometry and intracellular changes in the rat testis. Tissue Cell 41, 105-111 http://dx.doi.org/10.1016/j.tice.2008.07.006

Kojima M., Hosoda H., Date Y., Nakazato M., Matsuo H., Kangawa K. (1999): Ghrelin is a growth-hormone-releasing acylated peptide from stomach. Nature 402, 656-660 http://dx.doi.org/10.1038/45230

Lebrethon M. C., Aganina A., Fournier M., Gerard A., Parent A. S., Bourguignon J. P. (2007): Effects of in vivo and in vitro administration of ghrelin, leptin and neuropeptide mediators on pulsatile gonadotrophin-releasing hormone secretion from male rat hypothalamus before and after puberty. J. Neuroendocrinol. 19, 181-188 http://dx.doi.org/10.1111/j.1365-2826.2006.01518.x

Lim C. T., Kola B., Korbonits M. (2011): The ghrelin/GOAT/GHS-R system and energy metabolism. Rev. Endocr. Metab. Disord. 12, 173-186 http://dx.doi.org/10.1007/s11154-011-9169-1

Lorenzi T., Meli R., Marzioni D., Morroni M., Baragli A., Castellucci M., Gualillo O., Muccioli G. (2009): Ghrelin: a metabolic signal affecting the reproductive system. Cytokine Growth Factor Rev. 20, 137-152 http://dx.doi.org/10.1016/j.cytogfr.2009.02.003

Martini A. C., Fernandez-Fernandez R., Tovar S., Navarro V. M., Vigo E., Vazquez, M. J., Davies J. S., Thompson N. M., Aguilar E., Pinilla L., Wells T., Dieguez C., Tena-Sempere M. (2006): Comparative analysis of the effects of ghrelin and unacylated ghrelin on luteinizing hormone secretion in male rats. Endocrinology 147, 2374-2382 http://dx.doi.org/10.1210/en.2005-1422

Milošević Lj. V., Stevanović D. M., Nešić D. M., Sosic-Jurjevic B. T., Ajdžanović V. Z., Starčević P. V., Severs W. B. (2010): Central effects of ghrelin on the adrenal cortex: a morphological and hormonal study. Gen. Physiol. Biophys. 29, 194-202 http://dx.doi.org/10.4149/gpb_2010_02_194

Plećaš B., Popović A., Jovović D., Hristić M. (1992): Mitotic activity and cell deletion in ventral prostate epithelium of intact and castrated oxytocin-treated rats. J. Endocrinol. Invest. 15, 249-253

Plećaš B., Glavaški A., Solarović T. (1997): Propranolol treatment affects ventral prostate blood vessels and serum testosterone concentrations in adult rats. Andrologia 29, 109-114

Reiter E., Bonnet P., Sente B., Dombrowicz D., de Leval J., Closset J., Hennen G. (1992): Growth hormone and prolactin stimulate androgen receptor, insulin-like growth factor-I (IGF-I) and IGF-I receptor levels in the prostate of immature rats. Mol. Cell Endocrinol. 88, 77-87 http://dx.doi.org/10.1016/0303-7207(92)90011-T

Reiter E., Kecha O., Hennuy B., Lardinois S., Klug M., Bruyninx M., Closset J., Hennen G. (1995): Growth hormone directly affects the function of the different lobes of the rat prostate. Endocrinology 136, 3338-3345 http://dx.doi.org/10.1210/en.136.8.3338

Roa J., Garcia-Galiano D., Castellano J. M., Gaytan F., Pinilla L., TenaSempere M. (2010): Metabolic control of puberty onset: new players, new mechanisms. Mol. Cell Endocrinol. 324, 87-94 http://dx.doi.org/10.1016/j.mce.2009.12.018 
Ruan W., Powell-Braxton L., Kopchick J. J., Kleinberg D. L. (1999): Evidence that insulin-like growth factor I and growth hormone are required for prostate gland development. Endocrinology 140, 1984-1989 http://dx.doi.org/10.1210/en.140.5.1984

Ryan P. D., Goss P. E. (2008): The emerging role of the insulinlike growth factor pathway as a therapeutic target in cancer. Oncologist 13, 16-24 http://dx.doi.org/10.1634/theoncologist.2007-0199

Sangiao-Alvarellos S., Vazquez M. J., Varela L., Nogueiras R., Saha A. K., Cordido F., Lopez M., Dieguez C. (2009): Central ghrelin regulates peripheral lipid metabolism in a growth hormoneindependent fashion. Endocrinology 150, 4562-4574 http://dx.doi.org/10.1210/en.2009-0482

Seoane L. M., Tovar S., Baldelli R., Arvat E., Ghigo E., Casanueva F. F., Dieguez C. (2000): Ghrelin elicits a marked stimulatory effect on GH secretion in freely-moving rats. Eur. J. Endocrinol. 143, R7-9 http://dx.doi.org/10.1530/eje.0.143R007

Simanainen U., Lampinen A., Henneicke H., Brennan T. C., Heinevetter U., Harwood D. T., McNamara K., Herrmann M., Seibel M. J., Handelsman D. J., Zhou H. (2011): Long-term corticosterone treatment induced lobe-specific pathology in mouse prostate. Prostate 71, 289-297 http://dx.doi.org/10.1002/pros.21242

Sirotkin A. V., Chrenkova M., Nitrayova S., Patras P., Darlak K., Valenzuela F., Pinilla L., Tena-Sempere M. (2008): Effects of chronic food restriction and treatments with leptin or ghrelin on different reproductive parameters of male rats. Peptides 29, 1362-1368 http://dx.doi.org/10.1016/j.peptides.2008.03.011

Starčević V. P., Morrow B. A., Farner L. A., Keil L. C., Severs W. B. (1988): Long-term recording of cerebrospinal fluid pressure in freely behaving rats. Brain Res. 462, 112-117 http://dx.doi.org/10.1016/0006-8993(88)90592-6

Stevanović D., Milošević V., Nešić D., Ajdžanović V., Starčević V., Severs W. B. (2006): Central effects of ghrelin on serum growth hormone and morphology of pituitary somatotropes in rats. Exp. Biol. Med. (Maywood) 231, 1610-1615

Sun Y., Manuel Garcia J., Smith R. G. (2007): Ghrelin and growth hormone secretagogue receptor expression in mice during aging. Endocrinology 148, 1323-1329 http://dx.doi.org/10.1210/en.2006-0782

Takaya K., Ariyasu H., Kanamoto N., Iwakura H., Yoshimoto A., Harada M., Mori K., Komatsu Y., Usui T., Shimatsu A., Ogawa Y., Hosoda K., Akamizu T., Kojima M., Kangawa K., Nakao K. (2000): Ghrelin strongly stimulates growth hormone release in humans. J. Clin. Endocrinol. Metab. 85, 4908-4911 http://dx.doi.org/10.1210/jc.85.12.4908
Tanaka M., Hayashida Y., Nakao N., Nakai N., Nakashima K. (2001): Testis-specific and developmentally induced expression of a ghrelin gene-derived transcript that encodes a novel polypeptide in the mouse. Biochim. Biophys. Acta 1522, 62-65

Tena-Sempere M. (2008): Ghrelin and reproduction: ghrelin as novel regulator of the gonadotropic axis. Vitam. Horm. 77, 285-300 http://dx.doi.org/10.1016/S0083-6729(06)77012-1

Tena-Sempere M., Barreiro M. L., Gonzalez L. C., Gaytan F., Zhang F. P., Caminos J. E., Pinilla L., Casanueva F. F., Dieguez C., Aguilar E. (2002): Novel expression and functional role of ghrelin in rat testis. Endocrinology 143, 717-725 http://dx.doi.org/10.1210/en.143.2.717

Theander-Carrillo C., Wiedmer P., Cettour-Rose P., Nogueiras R., Perez-Tilve D., Pfluger P., Castaneda T. R., Muzzin P., Schurmann A., Szanto I., Tschop M. H., Rohner-Jeanrenaud F. (2006): Ghrelin action in the brain controls adipocyte metabolism. J. Clin. Invest. 116, 1983-1993 http://dx.doi.org/10.1172/JCI25811

Tschop M., Smiley D. L., Heiman M. L. (2000): Ghrelin induces adiposity in rodents. Nature 407, 908-913 http://dx.doi.org/10.1038/35038090

Un-no T., Hayami S., Nobata S., Sudoko H., Honma S., Fujita K., Ozono S. (2007): Neonatal exposure to estrogen in the Wistar rat decreases estrogen receptor-beta and induces epithelial proliferation of the prostate in the adult. Urol. Int. 79, 345-351 http://dx.doi.org/10.1159/000109721

Vilamaior P. S., Taboga S. R., Carvalho H. F. (2006): Postnatal growth of the ventral prostate in Wistar rats: a stereological and morphometrical study. Anat. Rec. A Discov. Mol. Cell Evol. Biol. 288, 885-892 http://dx.doi.org/10.1002/ar.a.20363

Wang L., Fang F., Li Y., Zhang Y., Pu Y., Zhang X. (2011): Role of ghrelin on testosterone secretion and the mRNA expression of androgen receptors in adult rat testis. Syst. Biol. Reprod. Med. 57, 119-123

Weibel E. R., Gomez D. M. (1962): A principle for counting tissue structures on random sections. J. Appl. Physiol. 17, 343-348

Wren A. M., Small C. J., Ward H. L., Murphy K. G., Dakin C. L., Taheri S., Kennedy A. R., Roberts G. H., Morgan D. G., Ghatei M. A., Bloom S. R. (2000): The novel hypothalamic peptide ghrelin stimulates food intake and growth hormone secretion. Endocrinology 141, 4325-4328 http://dx.doi.org/10.1210/en.141.11.4325

Received: July 22, 2011

Final version accepted: December 23, 2011 